\title{
IN.PACT ${ }^{\mathrm{TM}}$ Admiral ${ }^{\mathrm{TM}}$ drug-coated balloons in peripheral artery disease: current perspectives
}

This article was published in the following Dove Press journal:

Medical Devices: Evidence and Research

\section{Sho Torii \\ Frank D Kolodgie \\ Renu Virmani \\ Aloke $V$ Finn}

Cardiovascular Pathology, CVPath Institute, Inc., Gaithersburg, MD, USA
Correspondence: Renu Virmani CVPath Institute, Inc., 19 Firstfield Road, Gaithersburg, MD 20878, USA

$\mathrm{Tel}+\mathrm{I} 3012083570$

Fax +I 30I 2083745

Email rvirmani@CVPath.org

\begin{abstract}
Endovascular therapy has evolved as a main treatment option especially in patients with short $(<25 \mathrm{~cm})$ femoropopliteal lesion. The latest guideline recommends the use of drugeluting devices (both drug-coated balloons [DCBs] and drug-eluting stents) in short femoropopliteal lesions as class IIb recommendation. DCB usage is also recommended for in-stent restenosis lesions (class IIb). DCBs are a more attractive treatment option because the lack of metal prosthesis allows for more flexibility in future treatment options including the option of treating nonstenting zones, previously DCB-treated zones with DCBs again. The IN.PACT TM Admiral ${ }^{\mathrm{TM}}$ DCB has shown promising clinical performance in several randomized control trials and global registries, and is currently the market DCB leader for the treatment of femoropopliteal lesions with more than 200,000 patients treated thus far. Currently, more than 10 DCBs have received Conformité Européene mark for the treatment of femoropopliteal atherosclerotic disease. Three of these (including IN.PACT Admiral DCBs) have also received Food and Drug Administration approval in the USA. However, some Conformité Européene-marked DCBs have failed to show consistent results in their clinical studies suggesting all DCBs are not created equal. Each DCB is unique (ie, drug type, drug dose, crystallinity, and excipient) with different clinical outcomes. In the current review, we will focus on the preclinical and clinical results of not only IN.PACT Admiral DCB, but also the other currently available DCBs.
\end{abstract}

Keywords: drug-coated balloon, superficial femoral artery, percutaneous transluminal angioplasty, peripheral artery disease, drug-eluting stent, critical limb ischemia

\section{Introduction}

Peripheral arterial disease (PAD) contributes to significant morbidity and mortality, affecting approximately 202 million adults worldwide in 2010. ${ }^{1,2}$ The global prevalence of PAD between 2000 and 2010 has increased by $23.5 \%$ in low-income and middle-income countries, and $13.1 \%$ in high-income countries. ${ }^{3}$ The prevalence of asymptomatic PAD is in the range of 3\%-10\% in individuals 50-69 years increasing to $15 \%-20 \%$ in persons $>70$ years. ${ }^{4}$ PAD is primarily caused by atherosclerotic disease, with similar risk factors as coronary artery disease (CAD), ${ }^{5}$ with diabetes and smoking having the greatest impact. ${ }^{6,7}$ Diagnosis and management of atherosclerosis are critical in the treatment of PAD.

We have recently evaluated the pathological characteristics of legs in patients with history of abundant coronary risk factors, ${ }^{65}$ and also in patients with critical limb ischemia (CLI). ${ }^{8}$ The main findings of these studies were as follows: ${ }^{1}$ intimal and medial calcification (known as Mönckeberg calcification) more commonly 
observed in both femoropopliteal and infra-popliteal arteries; ${ }^{2}$ femoropopliteal arteries demonstrated higher prevalence of fibrocalcific plaque than that reported in coronary arteries; focal bone formation is also more frequently found in $83 \%$ of lower extremities of these patients, and is most commonly seen in femoropopliteal arteries; ${ }^{3}$ plaque rupture and calcified nodule are the major causes of acute thrombotic events in femoropopliteal arteries; ${ }^{4}$ half of the chronic total occlusion lesions in infra-popliteal arteries occurs secondary to distal emboli from upstream thrombotic lesions.

Given the lower risk of periprocedural complications with shorter hospital stays when compared with surgery, endovascular therapy (EVT) has evolved as a main treatment option especially in patients with short $(<25 \mathrm{~cm})$ femoropopliteal lesions. ${ }^{1,2}$ The latest ESC guideline recommends the use of drug-eluting devices (both drug-coated balloons [DCB] and drug-eluting stents [DES]) in short femoropopliteal lesions as class IIb recommendation. DCB usage is also recommended for in-stent restenosis (ISR) lesions (class IIb). ${ }^{1}$

However, there is a need for further improvement in the DCB/DES technology for optimal treatment of EVT. Target lesion revascularization (TLR) rate 5 years after DES implantation in femoropopliteal arteries is $17 \%,{ }^{9}$ which is higher than that reported in coronary arteries $(\sim 10 \%) .{ }^{10}$ In addition to the higher rate of stent fracture due to the changes in biomechanical forces after stent implantation, ${ }^{11}$ decreased wall shear stress along the axis of the stented segment ${ }^{12}$ contributes to restenosis. Although the prevalence of stent fracture has been significantly decreased with the latest generation DES
( $1.9 \%$ in the 5 years follow-up), ${ }^{9}$ DCBs are a more attractive treatment option because the lack of metal prosthesis allows for more flexibility in future treatment options including the option of treating nonstenting zones, previously DCB-treated zones with DCBs again.

The IN.PACT ${ }^{\mathrm{TM}}$ Admiral ${ }^{\mathrm{TM}}$ DCB (Medtronic Vascular, Santa Clara, CA, USA) has shown promising clinical performance in several randomized control trials (RCTS) and global registries, ${ }^{13-18}$ and is currently the market DCB leader for the treatment of femoropopliteal lesions with more than 200,000 patients treated thus far. ${ }^{19}$ Currently, more than 10 DCBs have received Conformité Européene (CE) mark for the treatment of femoropopliteal atherosclerotic disease. Three of these (including IN.PACT Admiral DCB) have also received Food and Drug Administration (FDA) approval in the USA (Table 1). However, some CE-marked DCBs have failed to show consistent results in their clinical studies suggesting all DCBs are not created equal. Each DCB is unique (ie, drug type, drug dose, crystallinity, and excipient) with different clinical outcomes. In the current review, we will focus on the preclinical and clinical results of not only IN.PACT Admiral DCB, but also the other currently available DCBs.

\section{Drug effect of DCBs}

Uncoated balloon angioplasty (BA) failed to show acceptable clinical outcomes, primarily due to high restenosis rates of $40 \%-50 \%$ at 12 months follow-up and lack of durability of the treatment effect. ${ }^{1,2}$ Mechanical stress due to BA causes injury to endothelial cells and the medial wall, promotes cracking of the plaque, and is followed by a repair mechanism

Table I CE-marked DCBs

\begin{tabular}{|c|c|c|c|c|c|}
\hline Device & Company & Drug & Coating/excipient & $\begin{array}{l}\text { Drug dose } \\
\left(\mu \mathrm{g} / \mathrm{mm}^{2}\right)\end{array}$ & $\begin{array}{l}\text { FDA } \\
\text { approva }\end{array}$ \\
\hline \multicolumn{6}{|l|}{ RCT result available } \\
\hline IN.PACT TM $^{\mathrm{TM}}$ Admiral ${ }^{\mathrm{TM}}$ & Medtronic Vascular, Santa Clara, CA, USA & Paclitaxel & Urea & 3.5 & Yes \\
\hline Lutonix $^{\circledR}$ & BARD, Murray Hill, NJ, USA & Paclitaxel & Polysorbate/sorbitol & 2.0 & Yes \\
\hline Stellarex $^{\mathrm{TM}}$ & Spectranetics, Colorado Springs, CO, USA & Paclitaxel & Polyethylene glycol & 2.0 & Yes \\
\hline Ranger $^{\mathrm{TM}}$ & Boston Scientific, Marlborough, MA, USA & Paclitaxel & Acetyl tributyl citrate 2 & 2.0 & No \\
\hline Passeo-18 Lux & Biotronik, Bülach, Switzerland & Paclitaxel & Butyryl-tri-hexyl citrate & 3.0 & No \\
\hline SeQuent ${ }^{\circledR}$ Please & B.Braun, Melsungen, Germany & Paclitaxel & Resveratrol & 3.0 & No \\
\hline \multicolumn{6}{|l|}{ Under RCT vs BA } \\
\hline SurVeil & SurModics, MN, USA & Paclitaxel & Proprietary photolink ${ }^{\circledR}$ & 3.2 & No \\
\hline LEGFLOW $^{\circledR}$ & Cardionovum, Bonn, Germany & Paclitaxel & Shelloic acid & 3.0 & No \\
\hline Luminor & iVascular, Barcelona, Spain & Paclitaxel & Organic ester & 3.0 & No \\
\hline \multicolumn{6}{|c|}{ Other DCBs without RCT } \\
\hline Elutax SV & Aachen Resonance, Luxembourg, Luxembourg & Paclitaxel & Dextrane & 2.2 & No \\
\hline BioPath (Freeway) & Biosensors, Singapore & Paclitaxel & Shelloic acid & 3.0 & No \\
\hline Kanshas $^{\mathrm{TM}}$ & Terumo, Tokyo, Japan & \begin{tabular}{|l|} 
Paclitaxel \\
\end{tabular} & I-Serine ethyl ester $\mathrm{HCl}$ & 3.2 & No \\
\hline XTREME TOUCH & Concept Medical Inc., Surat, India & Sirolimus & Phospholipid & 1.27 & No \\
\hline
\end{tabular}

Abbreviations: BA, balloon angioplasty; CE, Conformité Européene; DCBs, drug-coated balloons; FDA, Food and Drug Administration; RCT, randomized controlled trial. 
that involves platelet fibrin deposition, inflammation, release of growth factors, and smooth muscle cell (SMC) proliferation with subsequent deposition of matrix proteins. Stimulation of the cell cycle proteins and mitosis results in the final common pathway that leads to intimal hyperplasia by SMCs. ${ }^{20}$ Drugs used to coat DCBs inhibit SMC mitosis and thereby prevent restenosis. DCBs are composed of three key ingredients that help deliver the drug to the arterial wall; a standard percutaneous transluminal angioplasty (PTA) balloon catheter, anti-restenotic drug (predominantly paclitaxel), and an excipient for the rapid drug delivery and adherence of the drug to the arterial wall to allow continuous diffusion of the drug. Paclitaxel has the advantage of being highly lipophilic and is insoluble in water, binds to and stabilizes polymerized microtubules, thereby preventing mitotic division, apoptosis, and migration at the nanomolar level, preventing neointimal SMC accumulation. The IN.PACT Admiral is coated with the FreePac ${ }^{\circledR}$ coating solution, which is a proprietary coating with a matrix of paclitaxel on the expanded balloon surface. The FreePac coating contains a hydrophilic excipient (urea) that facilitates the release and transfer of paclitaxel to the target lesion. ${ }^{21}$ The paclitaxel dose is $3.5 \mu \mathrm{g} / \mathrm{mm}^{2}$ on the balloon surface. The FreePac coating was developed from the original Paccocath product, which had iopromide as an excipient showing significantly better clinical outcomes compared with PTA alone in the THUNDER randomized trial. ${ }^{22,23}$ Urea is hydrophilic and facilitates hydration of the coating that promotes release and transfers the paclitaxel from the balloon surface to the arterial wall. In addition, the excipient also promotes sustained solid-phase paclitaxel reservoirs in the tissue..$^{21}$ The solid-phase paclitaxel remains in the arterial wall for $>90$ days at therapeutic levels (data on file at Medtronic, manuscript under review), which results in longer-term anti-restenotic effect. ${ }^{69}$ Similar to the THUNDER trial, Liistro et al demonstrated greater efficacy with IN.PACT Admiral DCB + bare metal stents (BMS) when compared with PTA + BMS at both 6 and 12 months. ${ }^{24}$

\section{Drugs for lesions with PAD}

Although DES with Rapamycin analogs have shown superior clinical outcome in CAD compared with a DES with paclitaxel (TAXUS ${ }^{\text {TM; }}$ Boston Scientific, Natick, MA, USA), ${ }^{25}$ for femoropopliteal artery disease, self-expanding DES with Rapamycin analogs (sirolimus and everolimus) failed to show a sustained superior clinical outcomes compared with BMS in several RCTs. ${ }^{26,27}$ On the other hand, the two CE-marked self-expanding paclitaxel-based DES, Zilver $^{\circledR}$ PTX $^{\circledR}$ (Cook Medical, Bloomington, IN, USA) and Eluvia (Boston Scientific), have shown superior clinical outcomes, ${ }^{28,29}$ with sustained efficacy at 5 years in the former and 2 years in the latter after stent implantation. ${ }^{9}$ The main determinant of poor outcome with Rapamycin analogs may have been related to continuous expansion of the nitinol stent. Because of continuous expansion, there is greater injury to the arterial wall over time and greater interstrut distance, resulting in inadequate drug distribution and depletion of the drug availability that results in greater neointimal thickening and lack of efficacy. ${ }^{30,31}$ Paclitaxel eluting stents and balloons have been efficacious in above the knee PAD which may be due to properties of the drug itself as well as improvement in the nitinol stent platform.

Paclitaxel is primarily used because of its high stability and its lipophilic properties, which allow for passive adsorption through the cell membrane with long-term biologic effect. Paclitaxel binds to beta-tubulin and impairs microtubular disassembly and halts the cell replication. On the other hand, sirolimus inhibits mTOR complex 1 that promotes the translation of cyclin D1 mRNA, one of the cell cycle regulators. ${ }^{32}$ Several preclinical studies demonstrated neointimal inhibition by Rapamycin analogs-coated balloons, ${ }^{33}$ and one of them has received CE mark approval (XTREME TOUCH; Concept Medical Inc., Surat, India). The other Rapamycin analogs-coated balloon, SELUTIONTM DCB (MedAlliance SA, Irvine, CA, USA), has demonstrated relatively low clinically driven TLR (CD-TLR; $2.2 \%$ ) at 6 months follow-up in the first in man study (SELUTION trial, ClinicalTrials.gov ID: NCT02941224). However, there are no long-term data of RCTs available for Rapamycin analogscoated balloons, and further studies are needed.

\section{Drug efficacy of IN.PACT Admiral DCB in preclinical studies}

Technical features such as drug dose, ${ }^{34}$ crystallinity, drug coating integrity, and excipient ${ }^{35}$ all affect the differences in drug effect across all DCBs (Table 1). Several preclinical studies have been performed to compare the paclitaxel tissue levels and drug effect of DCBs. Gongora et al compared paclitaxel tissue levels up to 60 days following treatment with IN.PACT Pacific DCBs, Ranger ${ }^{\text {TM }}$ (Boston Scientific), and Lutonix ${ }^{\circledR}$ DCB (BARD, Murray Hill, NJ, USA) in the femoral artery of healthy swine. Although the drug levels were similar at 4 hours, however, higher drug levels were observed thereafter with the IN.PACT Pacific DCB up to 60 days. Neointimal inhibition after DCBs treatment in the ISR model of the familial hypercholesterolemic swine model was also evaluated. ${ }^{36}$ IN.PACT Pacific DCB demonstrated not only 
the highest paclitaxel tissue concentration when compared with Ranger and Lutonix DCB especially at 28 days after the treatment, but also the highest neointimal inhibition. As shown in Table 1, the drug levels on the balloon are highest for IN.PACT $\left(3.5 \mu \mathrm{g} / \mathrm{mm}^{2}\right)$ vs all other DCB (Ranger and Lutonix $2.0 \mu \mathrm{g} / \mathrm{mm}^{2}$ ). As the "ideal" tissue drug concentration to prevent restenosis in patients still remains unknown, further studies are needed.

Our preclinical studies with IN.PACT Admiral DCB also demonstrated similar differences in the histological findings after treatment of iliofemoral arteries when compared with Lutonix DCB in healthy swine models. Animals were treated with either IN.PACT Admiral DCB or Lutonix DCB and sacrificed at 0 day $(n=6$ in IN.PACT Admiral, $n=8$ in Lutonix DCB), 30 days ( $n=6$ per group), 60 days $(n=6$ per group), and 90 days ( $n=6$ in IN.PACT Admiral, $n=8$ in Lutonix DCB) after the treatment. Histologic sections of the treated lesions were examined for SMC cell loss (depth and circumferential) as an indicator of drug effect for both DCBs.
In addition to histological analysis, the mid sections of the treated arterial tissues at 0 and 90 days were also submitted for paclitaxel concentration. Although paclitaxel concentration at 0 day post treatment was similar between IN.PACT Admiral DCB and Lutonix DCB, IN.PACT Admiral DCB demonstrated significantly higher paclitaxel concentrations at 90 days. Histological analysis showed SMC loss peaked at 30-60 days following treatment, although SMC loss progressively decreases for both at 90 days. However the degree of loss remained significantly higher for IN.PACT Admiral DCB compared with Lutonix DCB (Figure 1; data on file at Medtronic, manuscript under review). ${ }^{69}$

\section{Long-term clinical outcome of IN.PACT Admiral DCB}

Of the available DCBs, IN.PACT Admiral has shown the longest duration of drug release and has demonstrated durable patency of femoropopliteal arteries in clinical trials compared with BA up to 4 years. IN.PACT SFA trial was a multicenter,

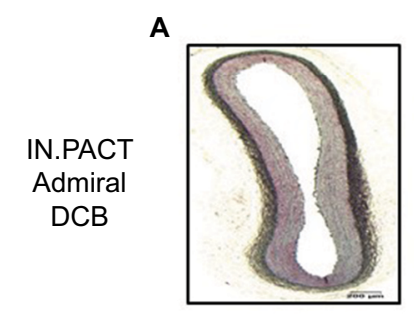

B

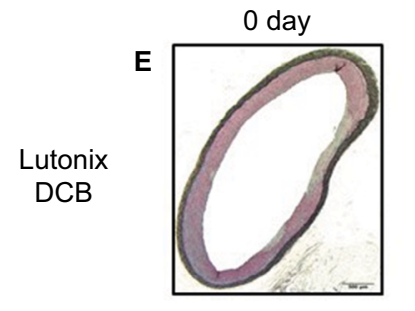

I

Medial SMC loss (depth)

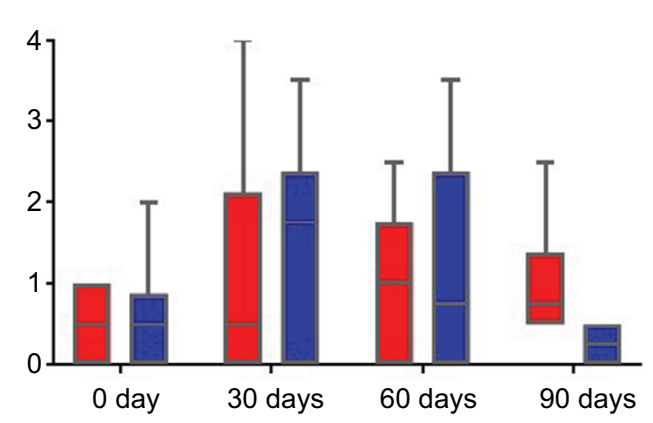

C

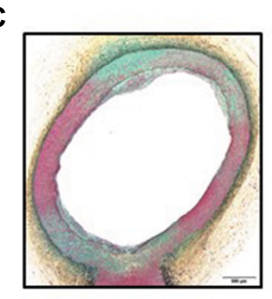

60 days

G

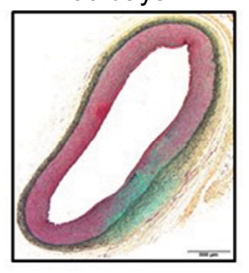

D

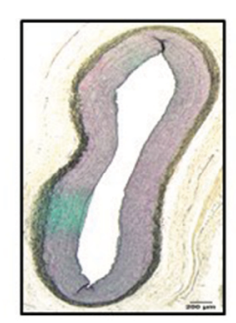

90 days

H

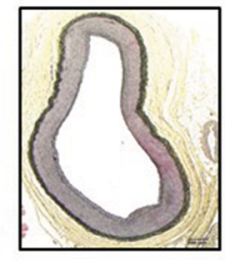

Medial SMC loss (circumference)

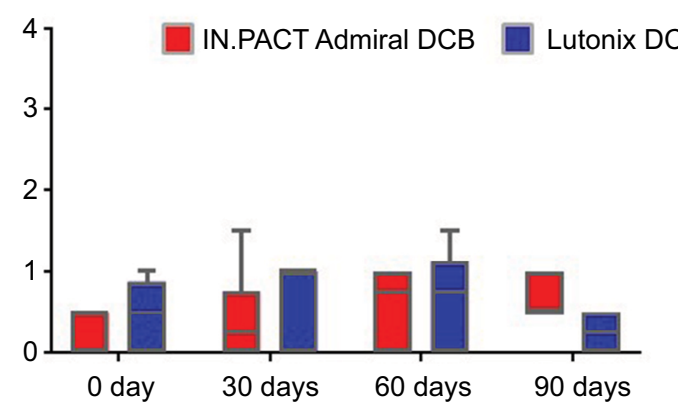

Figure I Representative images of histological changes after IN.PACT ${ }^{\text {TM }}$ Admiral ${ }^{\text {TM }}$ DCB and Lutonix ${ }^{\circledR}$ DCB treatments, and histological scores of drug biological effects in the swine femoral artery model.

Notes: Movat Pentachrome stained sections showing cross sections of the iliofemoral arteries after IN.PACT Admiral DCB and Lutonix DCB treatments (A-H). Note proteoglycan deposition (green) peaking at 30-60 days (B, C, F and $\mathbf{G}$ ) and decreased at long-term follow-up (90 days, D and $\mathbf{H})$. Both depth (I) and circumferential (J) medial SMC loss scores at long-term follow-up (90 days) were significantly greater for IN.PACT Admiral than Lutonix DCB.

Abbreviations: DCB, drug-coated balloon; SMC, smooth muscle cell. 
prospective, single-blind RCT to evaluate the efficacy and safety of IN.PACT Admiral compared with BA treatment in patients with femoropopliteal PAD. Patients were randomly assigned to DCB or BA in a 2:1 ratio (IN.PACT Admiral DCB; 220, BA; 111; Table 2). The primary efficacy endpoint was primary patency, defined as freedom from restenosis or CD-TLR at 12 months. IN.PACT Admiral DCB resulted in a significantly higher primary patency vs BA (IN.PACT Admiral DCB vs BA: $82.2 \%$ vs $52.4 \%$, respectively, $P<0.001$ ). IN.PACT Admiral DCB demonstrated higher freedom from CD-TLR compared with BA $(97.5 \%$ vs $79.3 \%$, respectively, $P<0.0001)$. The IN.PACT Admiral DCB also achieved the primary safety endpoint, with a composite of freedom from target limb major amputation and freedom from CD-TLR within 12 months. ${ }^{13}$ Three-year follow-up also demonstrated higher primary patency in patients treated with IN.PACT DCB compared with BA $(69.5 \%$ vs $45.1 \%$, respectively, $P<0.001)$ with higher freedom from CD-TLR $(84.5 \%$ vs $70.4 \%$, respectively, $P<0.001) .{ }^{37}$ Schneider et al recently presented 4 years outcomes of IN.PACT SFA trial at VIVA $2017 .{ }^{66}$ Four years follow-up assessment was performed with adjudicated CD-TLR conducted via telephone interview, which was defined as any reintervention of the target lesion due to symptoms or drop in ankle-brachial index (ABI) of $\geq 20 \%$ or $>0.15$ ) when compared with post-procedure baseline ABI. Freedom from CD-TLR at 4 years remained significantly higher in patients treated with IN.PACT Admiral DCB compared with BA (78.8\% vs $70.4 \%$, respectively, $\log$-rank $P=0.0399$ ). In addition, there were no target limb major amputations in both groups. In summary, IN.PACT Admiral demonstrated a durable drug effect compared with BA even at 4 years.

\section{RCTs of the other CE-marked DCBs and comparison with IN.PACT SFA}

RCTs comparing with BA treatment have also been performed for Lutonix DCB, Ranger, Stellarex ${ }^{\mathrm{TM}}$ (Spectranetics, Colorado Springs, CO, USA), Passeo-18 Lux (Biotronik, Bülach, Switzerland), and SeQuent ${ }^{\circledR}$ Please (B. Braun, Melsungen, Germany; Table 2). All these DCBs achieved their primary efficacy endpoint, although the definition of primary efficacy was different in many of these studies (Table 2). In RCT for IN.PACT SFA, ${ }^{13,15}$ Stellarex, ${ }^{38,39}$ and Lutonix DCB,,${ }^{40}$ the primary efficacy endpoint was primary patency, defined as freedom from restenosis and CD-TLR at 12 months followup. However, each RCT has a different definition for "restenosis", assessed as duplex ultrasound peak systolic velocity ratio (2.4 for IN.PACT Admiral DCB, 2.5 for Stellarex and
Lutonix). On the other hand, the primary efficacy endpoint of Ranger, ${ }^{41}$ Passeo-18 Lux, ${ }^{42}$ and SeQuent Please ${ }^{43}$ was late lumen loss (LLL) at 6 months assessed by angiography. Because patient and lesion characteristics were different in each of these RCTs, they cannot be compared directly. In addition, risk of bias, which is due to incomplete description of random sequence generation and assignment concealment, the infeasibility of operator blinding, and possible conflict of interest, is different in each RCT. ${ }^{44}$ IN.PACT Admiral DCB demonstrated the lowest rate of CD-TLR compared with the other DCBs. Further RCTs that directly compare different DCBs are needed to explore whether differences in clinical outcomes exists between the various CE-marked DCBs.

In addition to the inconsistent primary endpoints of each RCT, long-term follow-up results are available for only a few DCBs. Similar to IN.PACT SFA trial, LEVANT 2 trial was a multicenter, prospective, RCT to evaluate the efficacy and safety of Lutonix DCB compared with BA treatment in patients with femoropopliteal PAD. Patients were randomly assigned to $\mathrm{DCB}$ or $\mathrm{BA}$ in a 2:1 ratio (Lutonix DCB, 316; BA, 160; Table 2). The primary efficacy endpoint was primary patency, defined as freedom from restenosis or CD-TLR at 12 months. Lutonix DCB showed a significantly higher rate of primary patency vs BA (Lutonix DCB vs BA: $65.2 \%$ vs $52.6 \%$, respectively, $P=0.02$ ). Although the primary patency was significantly higher at 2 years, as presented by Rosenfield et al at SVS 2015, the statistical difference was of borderline significance ( $58.6 \%$ vs $53.0 \%$, respectively, $P=0.05){ }^{67}$

Two-year follow-up data are also available for the other two CE-marked DCBs, Stellarex (presented at LINC 2018) and SeQuent Please. ${ }^{45}$ In the ILLUMINATE EU RCT study, Stellarex demonstrated significantly greater freedom from CD-TLR compared with BA arm (Stellarex DCB vs BA: $88.9 \%$ vs $71.8 \%, P<0.001)$. In CONSEQUENT trial, SeQuent Please DCB arm demonstrated significantly lower TLR compared with BA arm (SeQuent Please DCB vs BA: $19.1 \%$ vs $40.6 \%, P=0.007)$.

\section{Downstream effect after DCB treatment}

Recently, three case reports demonstrated patients with painful rashes in lower leg, 1-2 weeks after DCB treatment suggesting downstream particulate emboli may have resulted in vasculitis or panniculitis. The rash disappeared in 3-4 weeks after oral steroid treatment. ${ }^{46-48}$

Our published preclinical study evaluated the extent of distal embolization following femoropopliteal DCB use in the porcine animal model..$^{49}$ In this study, downstream skeletal muscle and coronary band were histologically evaluated at 28 


\begin{tabular}{|c|c|c|c|c|c|c|c|c|c|c|c|c|c|c|c|}
\hline \multirow{10}{*}{ 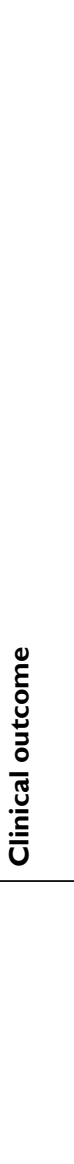 } & $\begin{array}{l}\overline{\overline{0}} \\
\text { हैं ঐ }\end{array}$ & 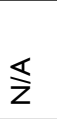 & & $\$$ & & $\stackrel{\S}{z}$ & \begin{tabular}{l|l} 
& 0 \\
\end{tabular} & $: \begin{array}{lll}n & 0 \\
0 & 0 & 0 \\
0\end{array}$ & $\frac{\hbar}{z}$ & $\stackrel{s}{z}$ & 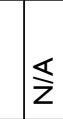 & 等 & $\stackrel{\aleph}{z}$ & & 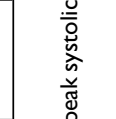 \\
\hline & 」Ј & 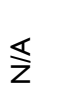 & & 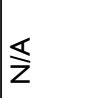 & & סָ & $\ll$ & 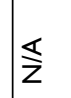 & $\frac{\$}{z}$ & రై & $\tilde{o}_{0}^{0}$ & S? & ठั & & \\
\hline & 」ૅ & $\$$ & & $\frac{s}{z}$ & & 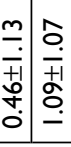 & 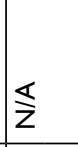 & 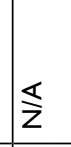 & $\underline{z}$ & 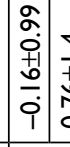 & 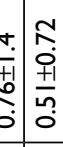 & 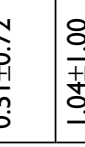 & : & 点 & 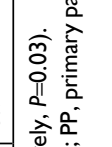 \\
\hline & 孚 & $\begin{array}{l}\overline{8} \\
\dot{0} \\
\mathrm{v}\end{array}$ & & 告 & & 气 & స̃. & 㝰 & $\overline{0}$ & in & $\stackrel{\infty}{0}$ & $\stackrel{\circ}{\circ}$ & $\overline{8}$ & & \\
\hline & ْ & $N$ & $\bar{N}$ & $m$ & 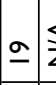 & 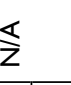 & $\leqslant$ & 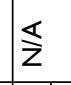 & $0=$ & 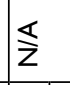 & $\theta$ & $\circ$ & $\widehat{z}$ & & \\
\hline & $\stackrel{\mathscr{r}}{\vec{F}}$ ๑ & $m$ & $|\bar{N}|$ & $m$ & 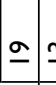 & $\underline{m} \approx$ & $\cong \simeq$ & 0 으 & $0 \leqslant \frac{Z}{Z}$ & 0 & $v \stackrel{\Sigma}{z}$ & $\Sigma$ & $a$ & $\bar{m}$ & \\
\hline & 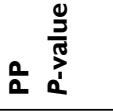 & $\overline{8}$ & & $\overline{8}$ & & $\$$ & ర్ & 苂 & $\overline{8}$ & 峞 & $\$$ & 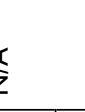 & 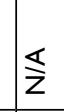 & & \\
\hline & $\stackrel{a}{a}$ & $\infty$ & กิ & $\infty$ & $\stackrel{\infty}{+} \mathfrak{r}$ & $\begin{array}{ll}\mathbf{g} \\
\end{array}$ & ถి & 12 & 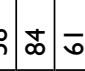 & 25 & $\stackrel{s}{z}$ & $\overleftarrow{z}$ & $\widehat{\Sigma}$ & & \\
\hline & 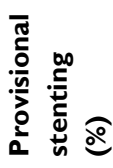 & $r$ & $\underline{m}$ & $\sigma$ & $\mathrm{m}$ & $m \simeq$ & $\min$ & 0 & $0 \underline{-}$ & $\bar{N}=$ & $=1$ & $\tilde{A}$ & i & $\underline{\sigma}$ & $\frac{0}{\lambda}$ \\
\hline & 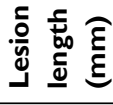 & $\infty$ & \begin{tabular}{|l|}
$\infty$ \\
$\infty$
\end{tabular} & $\alpha$ & $\infty$ & $\bar{\infty} \infty$ & 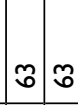 & 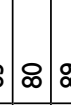 & 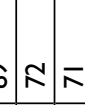 & $\stackrel{\infty}{\infty}$ & 6 五 & 8 & $\underline{\underline{m}}$ & $\stackrel{2}{\simeq}$ & \\
\hline \multirow{3}{*}{ 总 } & $\stackrel{\circ}{v}$ @ & $\stackrel{2}{\text { స్ }}$ & ని & $\underline{-}$ & $\simeq=$ & $\bar{\tau} \bar{q}$ & $\bar{N} \mid \approx$ & 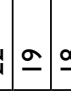 & $0 \simeq$ & $\stackrel{ \pm}{m}$ & $\dot{n}$ & : & $\ddot{\sim}$ & సิ & \\
\hline & 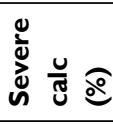 & $\infty$ & 0 & $n$ & $\sigma 2$ & $z$ & 으 $\infty$ & 72 & $f=0$ & $\stackrel{m}{2}$ & v & E & 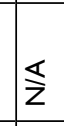 & & 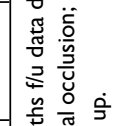 \\
\hline & Uั & \multicolumn{2}{|l|}{$\S$} & & & 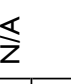 & : & $\mathbb{z}$ & & 25 & \multicolumn{2}{|l|}{$z$} & \multicolumn{2}{|l|}{$\$$} & \\
\hline \multirow[b]{6}{*}{ 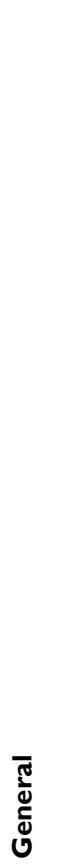 } & $=$ & సి & $E$ & $\infty$ & $\approx$ & ชั กิ & $\frac{0}{m} \stackrel{\circ}{0}$ & ¿ & $\stackrel{2}{0}$ & $\pi$ & i & 户 & $\stackrel{\infty}{\wedge}$ & & \\
\hline & 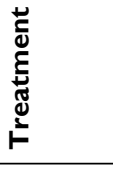 & $\begin{array}{l}\bar{U} \\
\bar{\alpha} \\
\underline{2} \\
\underline{z} \\
\end{array}$ & & 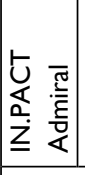 & $\varangle$ & 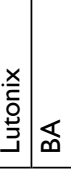 & 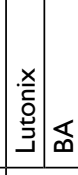 & 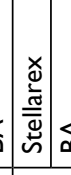 & 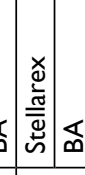 & 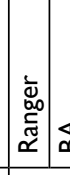 & & 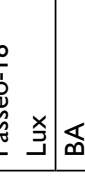 & & & \\
\hline & ڤั̀ & $\stackrel{+}{i}$ & & $\stackrel{i}{4}$ & & z & $\stackrel{\text { no }}{n}$ & $\stackrel{\text { in }}{\mathrm{i}}$ & $\stackrel{\sim}{i}$ & $\stackrel{\Delta}{i}$ & $z$ & 2 & $\Sigma$ & & \\
\hline & 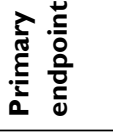 & 竞 & & 芜 & & $\frac{J}{\sum_{0}}$ & $\sum_{\substack{n \\
\alpha}}$ & 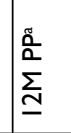 & $\sum_{\substack{a \\
\alpha}}$ & 当 & $\sum_{0}^{J}$ & L & $\sum_{\Sigma}^{J}$ & & \\
\hline & 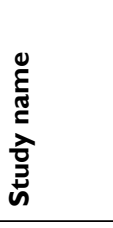 & 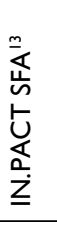 & & 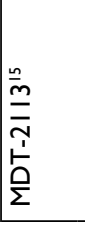 & & 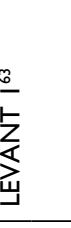 & 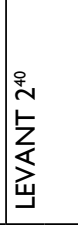 & 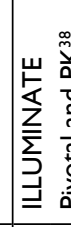 & 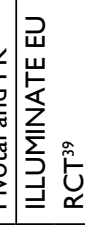 & 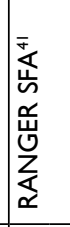 & 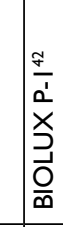 & ta & 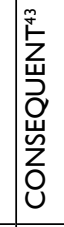 & & \\
\hline & $\begin{array}{l}\stackrel{0}{0} \\
\sum_{0}^{0} \\
0 \\
0 \\
0\end{array}$ & \multicolumn{3}{|c|}{ 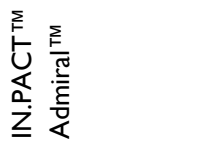 } & & & 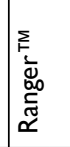 & & 䓪 & 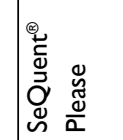 & & \\
\hline
\end{tabular}


and 90 days after treatment with single or overlapping $(3 \times)$ IN.PACT Admiral DCB vs Lutonix DCB to femoral arteries of healthy swine. Downstream paclitaxel concentration was also measured. Morphometric analysis of overlapping DCBs demonstrated numerically higher neointimal inhibition in IN.PACT Admiral DCB compared with Lutonix DCB at 28 days after the treatment. In addition, SMC loss score (both depth and circumference) was significantly higher for IN.PACT Admiral than Lutonix DCB. The percentage of sections with vascular changes in the downstream nontarget tissues was significantly higher at 90 days with overlapping $(\times 3)$ IN.PACT Admiral DCB compared with Lutonix DCB (IN.PACT Admiral DCB vs Lutonix DCB: $46.2 \%$ vs $0.0 \%$, $P=0.01)$, with similar trends observed at 28 days following single ( $15.4 \%$ vs $7.7 \%$, respectively, $P=0.04)$ or multiple $(\times 3)$ DCB usage ( $38.5 \%$ vs $7.7 \%$, respectively, $P=0.07$ ). Paclitaxel concentration in nontarget skeletal muscle and coronary band was also significantly higher in IN.PACT Admiral DCB com- pared with Lutonix DCB. ${ }^{49}$ Multiple DCB usage in a single lesion is common in the real-world daily clinical practice; therefore, drug levels achieved at site of treatment are likely different in single vs overlapped DCB.

We have also compared the downstream effect of overlapping IN.PACT Admiral DCB, Ranger, and Stellarex at 28 days utilizing similar methods as described in our previous study in the healthy swine femoral artery model. ${ }^{65}$ The percentage of sections with vascular changes in downstream nontarget tissues was similar for all three DCBs (IN. PACT vs Ranger vs Stellarex: $42.9 \%$ vs $25.0 \%$ vs $28.6 \%$, respectively, $P=0.2$ ). The downstream level of paclitaxel concentration in skeletal muscle was significantly higher for IN.PACT $(P=0.01)$ compared with Ranger and Stellarex. These two preclinical studies suggest that IN.PACT Admiral has a high prevalence of distal emboli compared with Lutonix DCB, Ranger, and Stellarex (Figure 2), although the difference between IN.PACT Admiral, Ranger, and Stel-

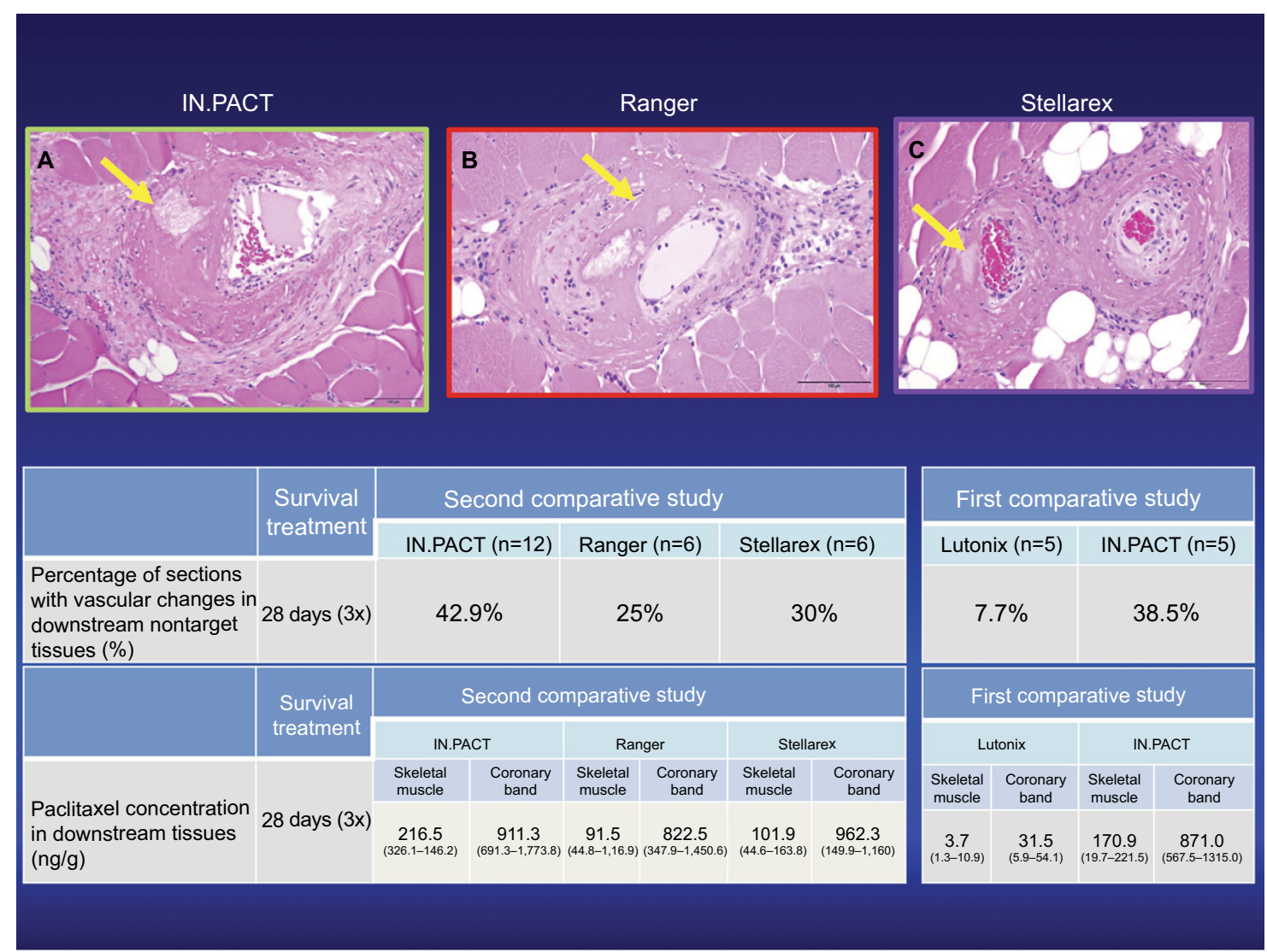

Figure 2 Representative images of downstream nontarget skeletal muscle and coronary band tissues from healthy swine after treatment of femoral arteries and downstream incidence of distal embolization after treatment with overlapping DCBs at 28 days follow-up.

Notes: Hematoxylin and eosin stained sections showing embolic crystalline material after IN.PACT ${ }^{\mathrm{TM}}$ Admiral ${ }^{\mathrm{TM}} \mathrm{DCB}(\mathbf{A})$, Ranger ${ }^{\mathrm{TM}}(\mathbf{B})$, and Stellarex ${ }^{\mathrm{TM}}(\mathbf{C})$ treatment (yellow arrows in top row) embedded in fibrin.

Source: Reproduced with permission from Reprinted from Journal of Vascular and Interventional Radiology, 27, Frank D. Kolodgie, Erica Pacheco, Kazuyuki Yahagi, Hiroyoshi Mori, Elena Ladich, Renu Virmani, Comparison of Particulate Embolization after Femoral Artery Treatment with IN.PACT Admiral versus Lutonix 035 PaclitaxelCoated Balloons in Healthy Swine, 1676-1685.e2., @ 2016, with permission from Elsevier. And Reprinted from Journal of Vascular and Interventional Radiology, Sho Torii, Hiroyuki Jinnouchi, Atsushi Sakamoto, Maria E. Romero, Frank D. Kolodgie, Renu Virmani, Aloke V. Finn, Comparison of Biologic Effect and Particulate Embolization after Femoral Artery Treatment with Three Drug-Coated Balloons in Healthy Swine Model, Epub ahead of print., (C) 2018, with permission from Elsevier. ${ }^{68}$

Abbreviation: DCBs, drug-coated balloons. 
larex was of borderline significance. One possible reason for the higher prevalence of distal emboli may be the higher drug dose in IN.PACT compared with the other three DCBs (IN.PACT DCB vs the other DCBs, $3.5 \mu \mathrm{g} / \mathrm{mm}^{2}$ vs $2.0 \mu \mathrm{g} /$ $\mathrm{mm}^{2}$; Table 1). Also, Katsanos et al have demonstrated previously that higher paclitaxel dose $\left(>3.0 \mu \mathrm{g} / \mathrm{mm}^{2}\right)$ is the main determinant of significantly improved treatment effect, ie, decreased TLR in meta-analysis of the multiple RCTs and registry studies. ${ }^{34}$ Therefore, it is likely that a balance view must be adopted from a patient perspective; higher drug dose results in higher efficacy but also at the price of more distal emboli.

Despite a higher prevalence of distal emboli in the preclinical studies, there is no clear evidence in IN.PACT Admiral DCB in either $\mathrm{RCTs}^{13-18}$ or in real-world registries ${ }^{37,50}$ of embolic events. Amputation rates were not significantly different in IN.PACT vs BA. Also, the prevalence of downstream embolic events is difficult to evaluate, especially in the RCTs because the patients are generally healthy and highly selected with simple and short lesions. Therefore, it is likely that the patients enrolled in RCTs are less likely to suffer severe complications from emboli. Further studies utilizing larger number of patients with CLI are needed to clarify the impact of embolization.

\section{Clinical result of IN.PACT Admiral DCB for specific lesions $D C B$ for in-stent restenosis}

DCB is logically the best treatment option for ISR lesions, and it is recommended to be class IIb treatment in the latest guidelines. ${ }^{1}$ Several studies including prospective singlearm studies, ${ }^{51} \mathrm{RCT}^{50}$ and registries ${ }^{16,17}$ support the efficacy of IN.PACT Admiral DCB treatment for ISR lesions. The FAIR trial was a prospective, multicenter, RCT that compared safety and efficacy of IN.PACT Admiral DCB $(n=62)$ vs BA $(n=57)$ for the treatment of ISR in the femoropopliteal lesions. ${ }^{50}$ The primary efficacy endpoint was binary restenosis at 6 months. The IN.PACT Admiral DCB arm demonstrated significantly less prevalence of binary restenosis compared with BA arm (IN.PACT Admiral DCB vs BA: 15.4\% vs $44.7 \%, P=0.002$ ). Also, freedom from TLR at 12 months was significantly higher for IN.PACT Admiral DCB arm compared with BA arm (90.8\% vs 52.6\%, respectively, $P<0.001)$. Lutonix DCB also demonstrated acceptable results for ISR lesions. Freedom from TLR after Lutonix DCB treatment at 12 and 24 months was $90.7 \%$ and $84.6 \%$ in Lutonix Global SFA registry. ${ }^{52}$ In addition, a prospective multicenter RCT that is comparing safety and efficacy of Lutonix DCB is cur- rently ongoing (ClinicalTrials.gov Identifier: NCT02063672). These clinical studies suggest that IN.PACT Admiral or the other DCBs should be the primary treatment option for the treatment of ISR lesions.

\section{DCB in infrapopliteal (CLI) lesions}

According to the latest clinical guidelines, DCB usage for infrapopliteal lesions is not recommended ${ }^{1,2}$ mainly because of the negative result over BA treatment in the IN.PACT DEEP $^{53}$ and the BIOLUX P-II ${ }^{54}$ RCTs. In the IN.PACT DEEP trial, a total of 358 patients mostly with CLI were randomized to IN.PACT Amphirion DCB treatment group or BA treatment group. Coprimary efficacy outcomes were TLR and angiographic LLL at 12 months, and the primary safety endpoint was a 6-month composite of all-cause mortality, TLR, or major amputation. There were no differences in CD-TLR between IN.PACT Admiral DCB group and BA group with more complications in IN.PACT Amphirion DCB group with higher prevalence of major amputations (IN.PACT Amphirion DCB vs BA: $8.8 \%$ vs 3.6\%, $P=0.080$ ) and lower amputation-free survival $(81.1 \%$ vs $89.2 \%$, respectively, $P=0.057)$. It is conceivable that distal emboli and/or nontarget drug delivery of IN.PACT Amphirion DCB, an older generation of IN.PACT Admiral, might have been one of the reasons for the failure. In IN.PACT Amphirion, used in the IN.PACT DEEP trial, ${ }^{53}$ urea excipient and paclitaxel were "manually" coated "after" folding of the balloon, perhaps leading to variability in coating/drug load. ${ }^{55}$ This could have led to the nonuniform paclitaxel distribution on the balloon, resulting in the majority of paclitaxel being peeled away during delivery, resulting in less drug delivery as well as distal emboli. A recent real-world registry demonstrated efficacy and safety of Lutonix DCB in the treatment of infrapopliteal arteries; ${ }^{56}$ however, prospective RCTs comparing standard BA treatment are not available. There are two ongoing randomized clinical trials comparing EVT and surgical therapy ${ }^{57,58}$ to confirm efficacy of currently available DCBs in patients with CLI.

\section{DCB in heavily calcified lesions}

In 2014, Fanelli et al have demonstrated the effect of calcification on the efficacy of DCB during EVT of femoropopliteal lesions. ${ }^{59}$ In this study, 60 patients with de novo femoropopliteal lesions were treated with DCBs. The severity of calcification was evaluated with a combination of CT angiography (CTA), digital subtraction angiography (DSA), and intravascular ultrasound (IVUS). Patients were classified into eight groups according to circumferential and longitudinal distribution of calcification evaluated with CTA and DSA. These findings were further confirmed by IVUS images. Pro- 


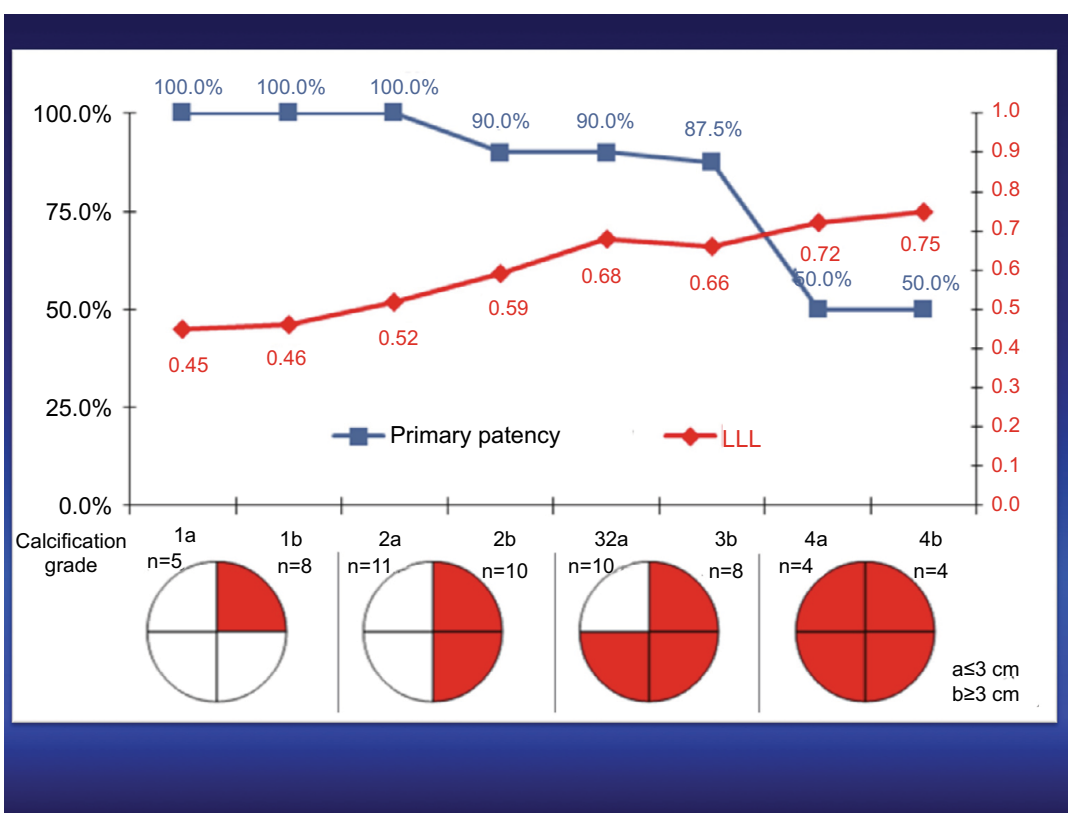

Figure 3 Primary patency and LLL at 12 months after the treatment in eight groups that were classified according to circumferential and longitudinal distribution of calcification.

Note: There is an inverse relationship between the primary patency and LLL with groups with severe calcification (4a and 4b).

Source: Reprinted by permission from Springer Nature Customer Service Centre GmbH: Springer Nature CardioVascular and Interventional Radiology Fanelli F, Cannavale A, Gazzetti M, et al. Calcium burden assessment and impact on drug-eluting balloons in peripheral arterial disease. Cardiovasc Intervent Radiol. 2014;37(4):898-907, ๑ 2014.59 Abbreviation: LLL, late lumen loss.
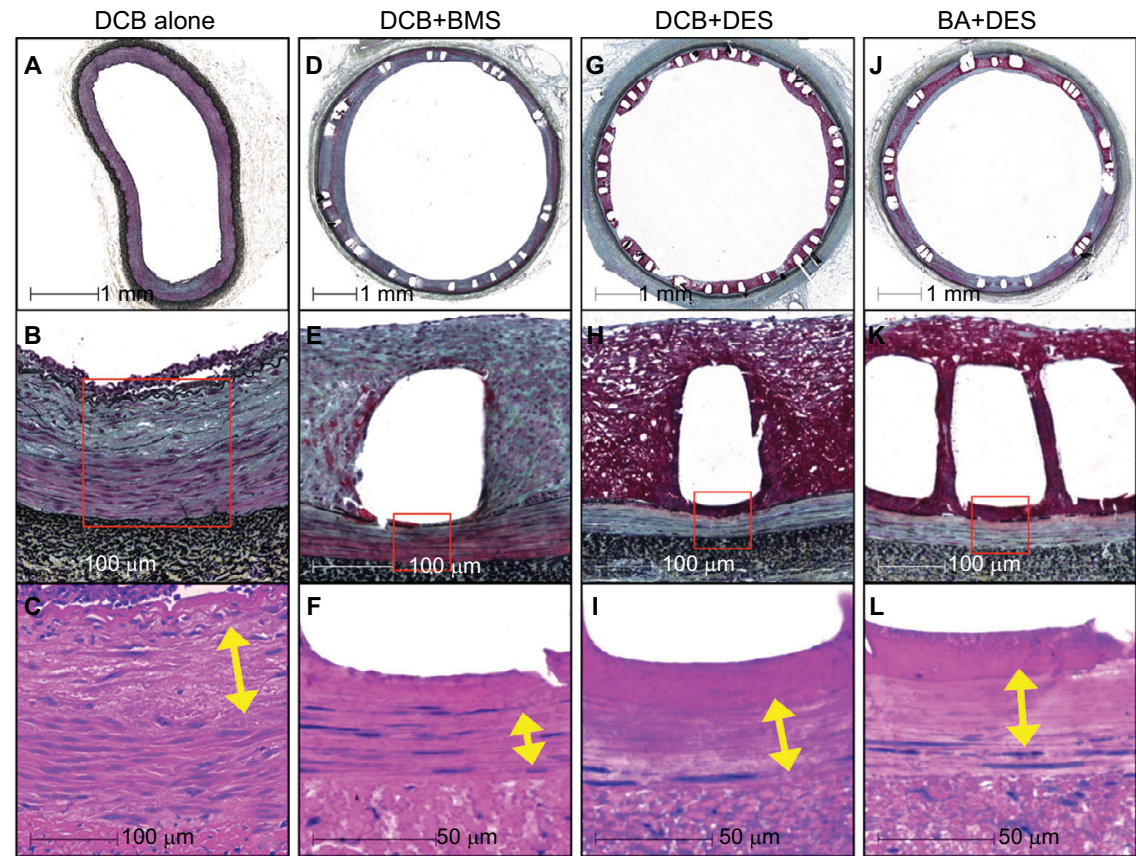

Figure 4 Representative histologic images of the biologic responses to $D C B+D E S, B A+D E S, D C B+B M S$, and $D C B$ alone in swine iliofemoral arteries.

Notes: Fibrin deposition in each treatment group is demonstrated in the middle panels, whereas depth of SMC loss is demonstrated with yellow arrows in the lower panels. Mild medial SMC loss with focal proteoglycan accumulation is observed in the DCB-alone group (A-C). Moderate medial SMC loss is observed in the DCB + BMS group, with minimal fibrin around stent struts (D-F). The greatest biologic drug effect is observed in the DCB + DES (G-I) and BA + DES (J-L) groups in the form of extensive medial SMC loss and extensive fibrin around stent struts.

Source: Reprinted from Journal of Vascular and Interventional Radiology, 29, Sho Torii,Kazuyuki Yahagi, Hiroyoshi Mori, Emanuel Harari, Maria E. Romero, Frank D. Kolodgie, Brandt Young, Anthony Ragheb, Renu Virmani, Aloke V. Finn, Biologic drug effect and particulate embolization of drug-eluting stents versus drug-coated balloons in healthy swine femoropopliteal arteries, 104I-1049., ( 2018 , with permission from Elsevier. ${ }^{61}$

Abbreviations: BA, balloon angioplasty; BMS, bare metal stents; DCB, drug-coated balloon; DES, drug-eluting stents; PTA, percutaneous transluminal angioplasty; SMC, smooth muscle cell. 
gressive worsening of clinical outcomes was observed as the severity of calcification increased (Figure 3). Further analyses confirmed that circumferential distribution of calcification is the most important determinant of DCB efficacy when compared with longitudinal distribution of calcification.

Schmidt et al also demonstrated that heavy calcification is an independent predictor of restenosis following DCB usage with significantly higher risk for the need of provisional stenting. ${ }^{18}$ Calcification likely acts as a barrier for the transfer and deposition of paclitaxel, leading to greater restenosis. In addition to the "barrier" effects of heavy calcification, a higher risk of recoil and residual stenosis after DCB treatment may also contribute to worse outcome.

We believe DES should be the first line of treatment for severely calcified femoropopliteal lesions since calcification of superficial femoral artery is not itself an independent predictor of restenosis after treatment with DES. ${ }^{60}$ Our preclinical studies in healthy swine iliofemoral artery model support this idea since DES treatment demonstrated significantly higher drug effect (medial SMC loss score) vs $\mathrm{DCB}^{61,62}$ (Figure 4). Importantly, the median value of circumferential medial SMC loss score was lower (1.2) in DCB than in DES (3.5) treatment groups (scores were dependent on the circumferential distribution of the drug as assessed by loss of SMCs with score of $1=<25 \% ; 2=25$ to $<50 \% ; 3=50$ to $<75 \%$, and $4=>75 \%$ ). The distribution of the treatment effect of DCB (not only circumferential but also transmural in distribution) is not as predictable and reproducible as those observed in DES in animal models. Nevertheless, in severely calcified femoropopliteal lesions, there remains a need for the improvement in DCB technology.

\section{Conclusion}

Three DCBs (IN.PACT Admiral DCB, Lutonix DCB, and Stellarex DCB) have been approved by the FDA following RCTs, and another two DCBs (SurVeil DCB and Ranger DCB) are still to be approved following completion of the trials. However, no trials have been performed to compare the head-to-head efficacy of all the three. All clinical trials have some differences in primary or secondary endpoints, therefore we cannot draw conclusions regarding each one's efficacy. Although Lutonix DCB was the first to get FDA approval (October 14, 2014) when compared with IN.PACT Admiral DCB (December 30, 2014), long-term results of time to first CD-TLR were significantly different between DCB and PTA at 4 years. Whereas, for Lutonix 035 the primary patency was $58.6 \%$ vs $53.0 \%$ for PTA. Further work of headto-head comparison between different DCBs in patients with PAD is needed to examine which DCBs are the most effective.

\section{Disclosure}

Sho Torii receives honoraria from Boston Scientific Japan, and Terumo Corporation, and research grants from SUNRISE lab. Renu Virmani and Aloke V Finn have received institutional research support from Abbott Vascular, BioSensors International, Biotronik, Boston Scientific, Cook Medical, Medtronic, and Terumo Corporation. Renu Virmani receives honoraria from Abbott Vascular, Boston Scientific, Cook Medical, Lutonix, Medtronic, and Terumo Corporation, and is a consultant for 480 Biomedical, Abbott Vascular, Medtronic, and W.L. Gore. The authors report no other conflicts of interest in this work.

\section{References}

1. Aboyans V, Ricco JB, Bartelink MEL, et al. 2017 ESC guidelines on the diagnosis and treatment of peripheral arterial diseases, in collaboration with the European Society for Vascular Surgery (ESVS): document covering atherosclerotic disease of extracranial carotid and vertebral, mesenteric, renal, upper and lower extremity arteries endorsed by: the European Stroke Organization (ESO) the task force for the diagnosis and treatment of peripheral arterial diseases of the European Society of Cardiology (ESC) and of the European Society for Vascular Surgery (ESVS). Eur Heart J. 2018;39(9):763-816.

2. Gerhard-Herman MD, Gornik HL, Barrett C, et al. 2016 AHA/ACC guideline on the management of patients with lower extremity peripheral artery disease: executive summary: a report of the American College of Cardiology/American Heart Association task force on clinical practice guidelines. Circulation. 2017;135(12):e686-e725.

3. Fowkes FG, Rudan D, Rudan I, et al. Comparison of global estimates of prevalence and risk factors for peripheral artery disease in 2000 and 2010 : a systematic review and analysis. Lancet. 2013;382(9901):1329-1340.

4. Norgren L, Hiatt WR, Dormandy JA, et al. Inter-society consensus for the management of peripheral arterial disease (TASC II). Eur J Vasc Endovasc Surg. 2007;33(Suppl 1):S1-S75.

5. Writing Committee to Develop Clinical Data Standards for Peripheral Atherosclerotic Vascular Disease, Creager MA, Belkin M, et al. 2012 ACCF/AHA/ACR/SCAI/SIR/STS/SVM/SVN/SVS key data elements and definitions for peripheral atherosclerotic vascular disease: a report of the American College of Cardiology Foundation/American Heart Association Task Force on Clinical Data Standards (Writing Committee to Develop Clinical Data Standards for Peripheral Atherosclerotic Vascular Disease). Circulation. 2012;125(2):395-467.

6. Diehm N, Shang A, Silvestro A, et al. Association of cardiovascular risk factors with pattern of lower limb atherosclerosis in 2659 patients undergoing angioplasty. Eur JVasc Endovasc Surg. 2006;31(1):59-63.

7. Lu JT, Creager MA. The relationship of cigarette smoking to peripheral arterial disease. Rev Cardiovasc Med. 2004;5(4):189-193.

8. Narula N, Dannenberg AJ, Olin JW. Pathology of peripheral artery disease in critical limb ischemia. J Am Coll Cardiol. 2018;72(18):2152-2163.

9. Dake MD, Ansel GM, Jaff MR, et al. Durable clinical effectiveness with paclitaxel-eluting stents in the femoropopliteal artery: 5-year results of the zilver PTX randomized trial. Circulation. 2016;133(15): 1472-1483.

10. Iqbal J, Serruys PW, Silber S, et al. Comparison of zotarolimus- and everolimus-eluting coronary stents: final 5-year report of the RESOLUTE all-comers trial. Circ Cardiovasc Interv. 2015;8(6):e002230.

11. Iida $\mathrm{O}$, Nanto $\mathrm{S}$, Uematsu M, et al. Effect of exercise on frequency of stent fracture in the superficial femoral artery. Am J Cardiol. 2006;98(2):272-274.

12. Schlager O, Zehetmayer S, Seidinger D, van der Loo B, Koppensteiner R. Wall shear stress in the stented superficial femoral artery in peripheral arterial disease. Atherosclerosis. 2014;233(1):76-82. 
13. Tepe G, Laird J, Schneider P, et al. Drug-coated balloon versus standard percutaneous transluminal angioplasty for the treatment of superficial femoral and popliteal peripheral artery disease: 12-month results from the IN.PACT SFA randomized trial. Circulation. 2015;131(5):495-502.

14. Brodmann M, Keirse K, Scheinert D, et al. Drug-coated balloon treatment for femoropopliteal artery disease: the IN.PACT global study de novo in-stent restenosis imaging cohort. JACC Cardiovasc Interv. 2017;10(20):2113-2123

15. Iida O, Soga Y, Urasawa K, et al. Drug-coated balloon vs standard percutaneous transluminal angioplasty for the treatment of atherosclerotic lesions in the superficial femoral and proximal popliteal arteries: oneyear results of the MDT-2113 SFA Japan randomized trial. J Endovasc Ther. 2018;25(1):109-117.

16. Stabile E, Virga V, Salemme L, et al. Drug-eluting balloon for treatment of superficial femoral artery in-stent restenosis. J Am Coll Cardiol. 2012;60(18):1739-1742.

17. Virga V, Stabile E, Biamino G, et al. Drug-eluting balloons for the treatment of the superficial femoral artery in-stent restenosis: 2-year follow-up. JACC Cardiovasc Interv. 2014;7(4):411-415.

18. Schmidt A, Piorkowski M, Görner H, et al. Drug-coated balloons for complex femoropopliteal lesions: 2-year results of a real-world registry. JACC Cardiovasc Interv. 2016;9(7):715-724.

19. Medtronic. IN.PACT Admiral Drug-Coated Balloon: Overview. 2018. Available from: https:/www.medtronic.com/us-en/healthcareprofessionals/products/cardiovascular/drug-coated-balloons/inpactdrug-coated-balloon.html. Accessed December 16, 2018.

20. Chaabane C, Otsuka F, Virmani R, Bochaton-Piallat ML. Biologica responses in stented arteries. Cardiovasc Res. 2013;99(2):353-363.

21. Peterson S, Hasenbank M, Silvestro C, Raina S. IN.PACT TM Admiral $^{\mathrm{TM}}$ drug-coated balloon: Durable, consistent and safe treatment for femoropopliteal peripheral artery disease. Adv Drug Deliv Rev. 2017;112:69-77.

22. Tepe G, Zeller T, Albrecht T, et al. Local delivery of paclitaxel to inhibit restenosis during angioplasty of the leg. $N \mathrm{Engl} \mathrm{J} \mathrm{Med}$. 2008;358(7):689-699.

23. Kelsch B, Scheller B, Biedermann M, et al. Dose response to paclitaxelcoated balloon catheters in the porcine coronary overstretch and stent implantation model. Invest Radiol. 2011;46(4):255-263.

24. Liistro F, Grotti S, Porto I, et al. Drug-eluting balloon in peripheral intervention for the superficial femoral artery: the DEBATE-SFA randomized trial (drug eluting balloon in peripheral intervention for the superficial femoral artery). JACC Cardiovasc Interv. 2013;6(12):1295-1302.

25. Palmerini T, Benedetto U, Biondi-Zoccai G, et al. Long-term safety of drug-eluting and bare-metal stents: evidence from a comprehensive network meta-analysis. J Am Coll Cardiol. 2015;65(23):2496-2507.

26. Lammer J, Bosiers M, Zeller T, et al. First clinical trial of nitinol selfexpanding everolimus-eluting stent implantation for peripheral arterial occlusive disease. J Vasc Surg. 2011;54(2):394-401.

27. Duda SH, Bosiers M, Lammer J, et al. Drug-eluting and bare nitinol stents for the treatment of atherosclerotic lesions in the superficial femoral artery: long-term results from the SIROCCO trial. J Endovasc Ther. 2006;13(6):701-710.

28. Müller-Hülsbeck S, Keirse K, Zeller T, Schroë H, Diaz-Cartelle J. Twelve-month results from the majestic trial of the eluvia paclitaxeleluting stent for treatment of obstructive femoropopliteal disease. $J$ Endovasc Ther. 2016;23(5):701-707.

29. Müller-Hülsbeck S, Keirse K, Zeller T, Schroë H, Diaz-Cartelle J. Longterm results from the majestic trial of the eluvia paclitaxel-eluting stent for femoropopliteal treatment: 3-year follow-up. Cardiovasc Intervent Radiol. 2017;40(12):1832-1838.

30. Zhao HQ, Nikanorov A, Virmani R, Jones R, Pacheco E, Schwartz LB. Late stent expansion and neointimal proliferation of oversized Nitinol stents in peripheral arteries. Cardiovasc Intervent Radiol. 2009;32(4):720-726.

31. Zhao HQ, Nikanorov A, Virmani R, Schwartz LB. Inhibition of experimental neointimal hyperplasia and neoatherosclerosis by local, stent-mediated delivery of everolimus. J Vasc Surg. 2012;56(6): $1680-1688$.
32. Habib A, Karmali V, Polavarapu R, et al. Sirolimus-FKBP12.6 impairs endothelial barrier function through protein kinase $\mathrm{C}-\alpha$ activation and disruption of the p120-vascular endothelial cadherin interaction. Arterioscler Thromb Vasc Biol. 2013;33(10):2425-2431.

33. Clever YP, Peters D, Calisse J, et al. Novel sirolimus-coated balloon catheter: in vivo evaluation in a porcine coronary model. Circ Cardiovasc Interv. 2016;9(4):e03543.

34. Katsanos K, Kitrou P, Spiliopoulos S, Diamantopoulos A, Karnabatidis D. Comparative effectiveness of plain BA, bare metal stents, drug-coated balloons, and drug-eluting stents for the treatment of infrapopliteal artery disease: systematic review and Bayesian network meta-analysis of randomized controlled trials. J Endovasc Ther. 2016;23(6):851-863.

35. Scheller B, Speck U, Schmitt A, Böhm M, Nickenig G. Addition of paclitaxel to contrast media prevents restenosis after coronary stent implantation. J Am Coll Cardiol. 2003;42(8):1415-1420.

36. Gongora CA, Shibuya M, Wessler JD, et al. Impact of paclitaxel dose on tissue pharmacokinetics and vascular healing: a comparative drugcoated balloon study in the familial hypercholesterolemic swine model of superficial femoral in-stent restenosis. JACC Cardiovasc Interv. 2015;8(8):1115-1123.

37. Schneider PA, Laird JR, Tepe G, et al. Treatment effect of drug-coated balloons is durable to 3 years in the femoropopliteal arteries: long-term results of the IN.PACT SFA randomized trial. Circ Cardiovasc Interv. 2018;11(1):e005891.

38. Krishnan P, Faries P, Niazi K, et al. Stellarex drug-coated balloon for treatment of femoropopliteal disease: twelve-month outcomes from the randomized ILLUMENATE pivotal and pharmacokinetic studies. Circulation. 2017;136(12):1102-1113.

39. Schroeder H, Werner M, Meyer DR, et al. Low-dose paclitaxel-coated versus uncoated percutaneous transluminal balloon angioplasty for femoropopliteal peripheral artery disease: one-year results of the ILLUMENATE European Randomized Clinical Trial (randomized trial of a novel paclitaxel-coated percutaneous angioplasty balloon). Circulation . 2017;135(23):2227-2236.

40. Rosenfield K, Jaff MR, White CJ, et al. Trial of a paclitaxel-coated balloon for femoropopliteal artery disease. NEngl J Med. 2015;373(2):145-153.

41. Bausback Y, Willfort-Ehringer A, Sievert H, et al. Six-month results from the initial randomized study of the ranger paclitaxel-coated balloon in the femoropopliteal segment. J Endovasc Ther. 2017;24(4):459-467.

42. Scheinert D, Schulte KL, Zeller T, Lammer J, Tepe G. Paclitaxelreleasing balloon in femoropopliteal lesions using a BTHC excipient: twelve-month results from the BIOLUX P-I randomized trial. J Endovasc Ther. 2015;22(1):14-21.

43. Tepe G, Gögebakan Ö, Redlich U, et al. Angiographic and clinical outcomes after treatment of femoro-popliteal lesions with a novel paclitaxel-matrix-coated balloon catheter. Cardiovasc Intervent Radiol. 2017;40(10):1535-1544.

44. Giacoppo D, Cassese S, Harada Y, et al. Drug-coated balloon versus plain balloon angioplasty for the treatment of femoropopliteal artery disease: an updated systematic review and meta-analysis of randomized clinical trials. JACC Cardiovasc Interv. 2016;9(16):1731-1742.

45. Albrecht T, Waliszewski M, Roca C, et al. Two-year clinical outcomes of the CONSEQUENT trial: can femoropopliteal lesions be treated with sustainable clinical results that are economically sound? Cardiovasc Intervent Radiol. 2018;41(7):1008-1014.

46. Ibrahim T, Dirschinger R, Hein R, Jaitner J. Downstream panniculitis secondary to drug-eluting balloon angioplasty. JACC Cardiovasc Interv. 2016;9(17):e177-e179.

47. Thomas SD, McDonald RR, Varcoe RL. Vasculitis resulting from a superficial femoral artery angioplasty with a paclitaxel-eluting balloon. J Vasc Surg. 2014;59(2):520-523.

48. Lake E, Twigg M, Farquharson F. Acute hypersensitivity reaction to femoral drug-coated balloons. Vasa. 2017;46(3):223-225.

49. Kolodgie FD, Pacheco E, Yahagi K, Mori H, Ladich E, Virmani R. Comparison of particulate embolization after femoral artery treatment with IN.PACT Admiral versus Lutonix 035 paclitaxel-coated balloons in healthy swine. J Vasc Interv Radiol. 2016;27(11):1676-1685. 
50. Krankenberg H, Tübler T, Ingwersen M, et al. Drug-coated balloon versus standard balloon for superficial femoral artery in-stent restenosis: the randomized femoral artery in-stent restenosis (fair) trial. Circulation. 2015;132(23):2230-2236.

51. Liistro F, Angioli P, Porto I, et al. Paclitaxel-eluting balloon vs. standard angioplasty to reduce recurrent restenosis in diabetic patients with in-stent restenosis of the superficial femoral and proximal popliteal arteries: the DEBATE-ISR study. $J$ Endovasc Ther. 2014;21(1):1-8.

52. Thieme M, Von Bilderling P, Paetzel C, et al. The 24-month results of the Lutonix global SFA Registry: worldwide experience with Lutonix drug-coated balloon. JACC Cardiovasc Interv. 2017;10(16):1682-1690.

53. Zeller T, Baumgartner I, Scheinert D, et al. Drug-eluting balloon versus standard balloon angioplasty for infrapopliteal arterial revascularization in critical limb ischemia: 12-month results from the IN.PACT DEEP randomized trial. J Am Coll Cardiol. 2014;64(15):1568-1576.

54. Zeller T, Beschorner U, Pilger E, et al. Paclitaxel-coated balloon in infrapopliteal arteries: 12-month results from the BIOLUX P-II randomized trial (BIOTRONIK'S-First in Man Study of the Passeo-18 LUX drug releasing PTA balloon catheter vs. the uncoated Passeo-18 PTA balloon catheter in subjects requiring revascularization of infrapopliteal arteries). JACC Cardiovasc Interv. 2015;8(12):1614-1622.

55. Laird JR, Armstrong EJ. Drug-coated balloons for infrapopliteal disease: digging deep to understand the impact of a negative trial. J Am Coll Cardiol. 2014;64(15):1577-1579.

56. Thieme M, Lichtenberg M, Brodmann M, Cioppa A, Scheinert D. Lutonix ${ }^{\circledR} 014$ DCB global Below the Knee Registry Study: interim 6-month outcomes. J Cardiovasc Surg. 2018;59(2):232-236.

57. Popplewell MA, Davies H, Jarrett H, et al. Bypass versus angioplasty in severe ischaemia of the leg - 2 (BASIL-2) trial: study protocol for a randomised controlled trial. Trials. 2016;17:11.

58. Menard MT, Farber A, Assmann SF, et al. Design and rationale of the best endovascular versus best surgical therapy for patients with critical limb ischemia (BEST-CLI) trial. J Am Heart Assoc. 2016;5(7):e003219.

59. Fanelli F, Cannavale A, Gazzetti M, et al. Calcium burden assessment and impact on drug-eluting balloons in peripheral arterial disease. Cardiovasc Intervent Radiol. 2014;37(4):898-907.
60. Iida O, Takahara M, Soga Y, et al. 1-year results of the ZEPHYR Registry (Zilver PTX for the Femoral Artery and Proximal Popliteal Artery): predictors of restenosis. JACC Cardiovasc Interv. 2015;8(8):1105-1112.

61. Torii S, Yahagi K, Mori H, et al. Biologic drug effect and particulate embolization of drug-eluting stents versus drug-coated balloons in healthy swine femoropopliteal arteries. J Vasc Interv Radiol. 2018;29(7):1041-1049.

62. Torii S, Yahagi K, Mori H. Safety of Zilver PTX drug-eluting stent implantation following drug-coated balloon dilation in a healthy swine model. J Endovasc Ther. 2018;25(1):118-126.

63. Scheinert D, Duda S, Zeller T, et al. The LEVANT I (Lutonix paclitaxelcoated balloon for the prevention of femoropopliteal restenosis) trial for femoropopliteal revascularization: first-in-human randomized trial of low-dose drug-coated balloon versus uncoated balloon angioplasty. JACC Cardiovasc Interv. 2014;7(1):10-19.

64. Steiner S, Willfort-Ehringer A, Sievert $\mathrm{H}$, et al. 12-month results from the first-in-human randomized study of the ranger paclitaxel-coated balloon for femoropopliteal treatment. JACC Cardiovasc Interv. 2018;11(10):934-941.

65. Torii S, Mustapha JA, Narula J, et al. Histopathologic Characterization of Peripheral Arteries in Subjects With Abundant Risk Factors. JACC Cardiovasc Imaging. Epub 2018 Dec 6.

66. Data Presented for Medtronic's In.Pact Admiral DCB [webpage on the Internet]. Wayne: Endovascular Today; 2017. Available from https:// evtoday.com/2017/09/12/data-presented-for-medtronics-inpact-admiral-dcb. Accessed December 21, 2018.

67. Bard's LEVANT 2 1-Year Data Published in NEJM; 2-Year Data Presented at SVS [webpage on the Internet]. Wayne: Endovascular Today; 2015. Available from https://evtoday.com/2015/06/bards-levant-2-1year-data-published-in-nejm-2-year-data-presented-at-SVS. Accessed December 21, 2018.

68. Torii S, Jinnouchi H, Sakamoto A, et al. Comparison of Biologic Effect and Particulate Embolization after Femoral Artery Treatment with Three Drug-Coated Balloons in Healthy Swine Model. J Vasc Interv Radiol. 2019;30(1):103-109.

69. Granada JF, Virmani R, Schulz-Jander D, Tunev S, Melder RJ. Rate of drug coating dissolution determines in-tissue drug retention and durability of biological efficacy. J Drug Deliv. In press 2018.
Medical Devices: Evidence and Research

\section{Publish your work in this journal}

Medical Devices: Evidence and Research is an international, peerreviewed, open access journal that focuses on the evidence, technology, research, and expert opinion supporting the use and application of medical devices in the diagnosis, monitoring, treatment and management of clinical conditions and physiological processes. The identification of novel

\section{Dovepress}

devices and optimal use of existing devices which will lead to improved clinical outcomes and more effective patient management and safety is a key feature. The manuscript management system is completely online and includes a quick and fair peer-review system. Visit http://www. dovepress.com/testimonials.php to read real quotes from authors. 